and a Department of Scientific and Industrial Research Fellow, who between them are responsible for field-work, fixed-station recording and data processing. The most urgent outstanding staff requirement is to strengthen the group on the theoretical side, and a second research fellowship is available for this purpose.

The first objective of the Research Group will be to exploit the possibilities of large seismic arrays for teleseismic studies. Several of these (including one at Eskdalemuir) are in service or under construction by the Atomic Energy Authority, each consisting of two lines of seismometers, $10 \mathrm{~km}$ or more in length, and having 11 seismometers in each line. Tho individual outputs are recorded side by side on magnetic tape.

The Authority analyses the data in a way which has been highly developed in radio astronomy, but which is comparatively new to seismology. First, the outputs from each line are added together, phase delays being introduced such that outputs corresponding to a set of waves travelling across the array in a given velocity and direction are added in phase, whereas the outputs from other types of event are distributed in time. As a result of this procedure, the ratio of the signal to the noise which is uncorrelated from one element to another is reduced in proportion to the square root of the number of elements. Disturbances which propagate coherently across the array, but at a velocity different from that which has been set up for playback, may be rejected more or less strongly than this (Fig. 2).

Next the summed outputs from the two lines are multiplied together, and the product smoothed so as to yield the cross-correlation of the two sets of data. As a result, signal components common to both lines are squared in the output, and therefore smooth to a positive value. Other signals, and random noise, yield products of fluctuating sign, the effects of which are reduced by the smoothing process. The results of this procedure are illustrated in Fig. 3, which shows a few of the outputs from one line of a cross, together with summed and correlated outputs for various lags. The correlator peaks for $S$ waves are clearly visible in the velocity range of $3 \cdot 4-4 \mathrm{~km} / \mathrm{sec}$, even though these waves are hard to see on the individual channels. The $P$-wave correlation at $6-8 \mathrm{~km} / \mathrm{sec}$ saturates the playback system.
In addition to its preparations for utilizing data from the Atomic Energy Authority arrays, the Edinburgh Research Group is building up a set of portable seismographs capable of detecting earth movements in the range of periods from $0 \cdot 1$ to 100 sec. The outputs will be recorded on magnetic tape, in a form similar to that used in the fixed arrays. When the equipment becomes operational, it should be possible to set it up either for conventional studies of explosions and local earthquakes, or as an array for the study of teleseisms. In the latter case, the use of self-contained field stations removes the limitations on the scale of the array, and hence on the range of wave-lengths which can be handled. On the other hand, it will not generally be possible to lay out a set of detectors in exact conformity with an optimum geometrical pattern, and we shall also lose the convenience of having the outputs recorded side by side on a single tape. The theoretical and instrumental problems which arise from this situation will provide a challenging field of investigation.

The third problem of interest to the group is to improve the performance of detecting elements, for it is clear that progress in many fields of seismology has been limited by the lack of records having adequate band-width and dynamic range, adequate freedom from cross-coupling and the effects of parasitic oscillations, and adequate long-term stability. During the past two years seismometers have been much improved, and in Great Britain we now have two types in production, having periods adjustable up to $3 \mathrm{sec}$ and $20 \mathrm{sec}$ respectively. In each of these the minimum frequencies of parasitic oscillations have been pushed up to more than 100 c.p.s., and excellent temperature stability has been achieved. With the aid of appropriate electronic eircuitry, there is now a good prospect of recording up to the limit of Earth noise, for all periods up to and including that of the fundamental period of the Earth's free oscillations.

The final problem of data acquisition is to set up the instruments in the right places. Although Scotland is the most favourable part of the United Kingdom for this purpose, there will be many types of problem for which it is not the best place in the world. For this reason we feel that our emphasis on mobility offers advantages over any approach which relies solely on the output of fixed stations.

\title{
OBITUARIES
}

\section{Prof. R. Ruggles Gates, F.R.S.}

Reginald Ruggles Gates, professor emeritus in the University of London, who died in London on August 12 at the age of eighty, held the chair of botany at King's College from 1921 until 1942. During this period, the Department grew considerably and attracted many research students, especially from overseas. He was made a Fellow of the Royal Society in 1931 and of King's College, London. He was a supporter and at various times an officer of many societies, especially the Eugenics Society, the Royal Anthropological Institute, the Linnean Society and the Royal Microscopical Society, of which he was an honorary member.

Gates was born on May 1, 1882, in Middletown, Nova Scotia, and educated at Mt. Alison University, McGill University and the University of Chicago. $\mathrm{He}$ also worked at the Woods Hole Marine Biological Station and at the Missouri Botanical Gardens. In London, he was lecturer in biology at St. Thomas's Hospital for two years from 1912, also lecturing on cytology at Bedford College and on heredity in relation to cytology at Oxford. During 1915-16 he was associate professor of zoology in the University of California; during 1917-18 he was instruetor in aerial gunnery to the Royal Air Force.

Gates had wide scientific interests, and he was a prolific writer. Much of his botanical work was descriptive, dealing with the cytology of various plants and with the microspecies of En nothera (evening primrose). The latter interest grew out of his early work on the mutants of EEnothera lamarckiana, discovered by Hugo de Vries, of whom he was an enthusiastic adherent. This led to his first book. 
The Mutation Factor in Evolution, published in 1915. He had strong and lasting views on the significance of mutations, not least those of large effect, in evolution, a view expressed in his Mutations and Evolution (1921).

The most important early work of Gates was the discovery (independently made by Miss Lutz) that the gigas mutant was tetraploid, with twice the chromosome number of the normal species. He also found triploid and trisomic mutants and the dominant rubricalyx, but the tetraploid was of especial interest since it had arisen directly from the normal diploid, differed from it in certain small characters and was isolated from it reproductively, hybrids between diploid and tetraploid being infertile. This first discovered instance of autototraploidy was a great stimulus to further research. His later work was on the evolution of the wild species of 2 Enothera, differing from one another only slightly, true breeding but easily crossed artificially, and perhaps rather impermanent in nature. In it he came to accept the views of Renner, Darlington and Cleland, though grudgingly and preserving somo of his own earlier misconceptions. The disagreements which were involved at least served to stimulate useful research.

Early in his scientific life, Gates developed a keen interest in human genetics and evolution and anthropology. His books, Heredity and Eugenics (1923) and Heredity in Man (1929), were good introductions to their subjects and undoubtedly stimulated many peoplo to gain an interest. Later, he published an immense two-volume compilation, Human Genetics (1946), followed by Human Ancestry (1947) and Pedigrees of Negro Families (1949). $\mathrm{He}$ was particularly interested in primitive peoples, collecting data on blood groups and other characteristies; more recently he investigated the genetics of skin pigmentation in negroids.

Gates was an inveterate traveller, whether collecting Enothera species in North America or traversing Africa in the pursuit of anthropological data. Travelling, indeed, was his sole recreation and one he never relinquished; in his seventies he visited Cuba, Mexico, Japan, Africa, Australia and India in furtherance of his studies of primitive peoples. $A$ Botanist in the Amazon Valley (1927) records observations which were often recounted to appreciativo undergraduate classes.

In outlook, Gates was primarily an observer, describer and systematist. Ho made experiments rather blindly, for he had little capacity for conceiving scientific hypotheses and for devising experimental tests. His early work, which was his best, was observational. He had a strong faith in what the microscope would reveal to his eye, scorning theoretical principles which controverted these observed 'facts'. His research students were closely supervised and expected daily to demonstrate a good cytological preparation; they were well trained in microscopical techniques, though conservatively.

As a colleague he was difficult to get to know at all intimately, for he seemed unable to relax and be at ease. Though generally mild-mannered, he could be most stubborn and would rarely admit to an error or retract a viow previously expressed. Through scientific controversy, not always on the right side, and his abundant writings, he certainly stimulated scientific thought and research.

His first wife was the late Dr. Marie Stopes, the well-known botanist and pioneer advocate of birth control and sex education; this marriage was annulled.
In 1930 he married Miss Jenny Williams, the singer, and in 1955 he married Mrs. Laura Greer (née Nowotny) of Texas. D. G. CATCheside

\section{Prof. F. P. Dwyer}

Prof. F. P. Dwyer, head of the Biological Inorganic Chemistry Unit in the Australian National University, died suddenly at his home in Canberra on June 22, from a coronary occlusion, at the age of fifty-one years.

Prof. Dwyer was born at Nelson Plains, New South Wales, and was educated at the Marist Brothers' Col. lege, Maitland, and the University of Sydney, where he graduated in 1932. From 1934 until 1945 he was senior lecturer and head of the Inorganic Chemistry Department at the Sydney Technical College, and during 1945-46 he was senior lecturer in inorganic chemistry in the University of Sydney. He was a visiting professor at Northwestern University during 1953-54, and in 1956 he was appointed to a new chair in inorganic chemistry in Pennsylvania State University; but he resigned from this appointment in 1957 without taking up the post to become reader and head of the Biological Inorganic Chemistry Unit in the John Curtin School of Medical Research of the Australian National University. For his outstanding contribution to inorganic chemistry he was elected, in 1960 , to one of the first personal professorships created in the Australian National University.

The versatility of Prof. Dwyer and the breadth of his interests in research are shown by more than 150 publications spread over the following topies: X-ray analysis, micro-analytical reagents and procedures, isomerism of the triazines and diazoamino compounds and their metal derivatives, the chemistry of platinum, palladium, rhodium, iridium, ruthenium and osmium, the redox potentials of simple compounds and complexes of the platinum metals, the optical activity and kinetics of racemization and substitution of Group 8 metal complexes, the diastereoisomeric offect and the principle of configurational activity, the stereochemistry of multidentate chelates, electron transfer reactions, the effects of metal complexes in biological systems and stereospecific influences in octahedral complexes.

For his work on diazoamino compounds, their metallic salts and metallic hydroxide lakes, he was awarded the degree of D.Sc. of the University of Sydney, the Royal Australian Chemical Institute's Rennie Medal (1940) and the Smith Medal (1945). In 1953 he was awarded the University of Melbourne's David Syme Medal and Prize for distinguished work in natural science.

In later years, as his international reputation grew, he held the George Fisher Baker non-resident lectureship in Cornell University (1954) and the first Chemical Society lectureship instituted by the Chemical Society of London for the purpose of encouraging the study of chemistry in Australian universities. Shortly before he died he had given a series of lectures at the invitation of the American Chemical Society. $\mathrm{He}$ is survived by his widow, two sons and a daughter.

Prof. Dwyer's colleagues will remember him for his outstanding ability, his personal charm, friendliness and modesty. His students will remember not only these qualities, but also his unfailing cheerfulness, sense of humour, encouragement and enthusiasm in the face of their many problems and errors. Scientifically, he is a great loss and he leaves many sad friends.
A. SARgEson 